\title{
Monitoring a photovoltaic system during the partial solar eclipse of August 2017
}

\author{
Santosh K. Kurinec ${ }^{1, *}$, Michal Kucer ${ }^{2}$, and Bill Schlein ${ }^{3}$ \\ ${ }^{1}$ Electrical \& Microelectronic Engineering, Rochester Institute of Technology, Rochester, NY, USA \\ ${ }^{2}$ Center of Imaging Science, Rochester Institute of Technology, USA \\ 3 Astronomy Section, Rochester Academy of Science (ASRAS), USA
}

Received: 21 November 2017 / Received in final form: 21 March 2018 / Accepted: 3 April 2018

\begin{abstract}
The power output of a $4.85 \mathrm{~kW}$ residential photovoltaic (PV) system located in Rochester, NY is monitored during the partial solar eclipse of August 21, 2017. The data is compared with the data on a day before and on the same day, a year ago. The area of exposed solar disk is measured using astrophotography every $16 \mathrm{~s}$ of the eclipse. Global solar irradiance is estimated using the eclipse shading, time of the day, location coordinates, atmospheric conditions and panel orientation. A sharp decline, as expected in the energy produced is observed at the time of the peak of the eclipse. The observed data of the PV energy produced is related with the model calculations taking into account solar eclipse coverage and cloudiness conditions. The paper provides a cohesive approach of irradiance calculations and obtaining anticipated PV performance.
\end{abstract}

Keywords: solar eclipse / photovoltaics / residential PV / solar irradiance / astro imaging

\section{Introduction}

Solar eclipse occurs rarely and whenever it happens, it sparks curiosity. A recently published Resource Letter by Pasachoff and Fraknoi [1] provides a guide to a wealth of literature on eclipse phenomena. A 60 - to 71-mile-wide band of totality crossed the Continental United States on August 21, 2017, that spanned the continent with totality on the centerline ranging from about $2 \mathrm{~min}$ in Oregon to a maximum of $2 \mathrm{~min} 40 \mathrm{~s}$ in Illinois and Kentucky [1,2]. Figure 1 shows the path of the solar eclipse obscuring approximately 1900 utility-scale solar photovoltaic (PV) power plants in the United States [3]. The location investigated in this study, Rochester, NY has the latitude of $43.16^{\circ} \mathrm{N}$ and longitude of $77.1^{\circ} \mathrm{W}$, experienced a $70 \%$ partial eclipse near the peak sunshine hours (1:13 PM-3:52 PM) [4]. The occurrence of this event close to the peak sunshine hours made this study interesting.

Solar cells, also called PV cells convert sunlight directly into electricity. PV gets its name from the process of converting light (photons) to electricity (voltage). According to a report by the International Energy Agency's PV Power System Program, 75 GW of solar PV were installed globally in 2016-bringing the installed global PV capacity to exceed $300 \mathrm{GW}$. That

\footnotetext{
* e-mail: skkemc@rit.edu
}

equates to producing 375 billion kilowatt-hours of solar power each year, which represents 1.8 percent of the electricity demand of the planet [5].

Recently, NERC ((North American Electric Reliability Corporation) released a white paper in April 2017 [6], suggesting the impact of the August 2017 eclipse on the PV plants in the US in line with what Regional Group Continental Europe and Synchronous Area Great Britain, did for the March 20, 2015 eclipse [7]. According to the NERC report, Arizona could expect to experience a brief interruption in about 70 percent of its rooftop solar generation, followed by New York at 68 percent, Utah at 39 percent, and Nevada at 24 percent. In these states, homes and businesses that normally generate most of their daytime power from rooftop solar PV panels will compensate by reducing energy use and/or temporarily drawing electricity from the grid. Grid operators in Europe, after months of planning, managed to avoid blackouts and huge power fluctuations from a nearly complete solar eclipse on March 20, 2015. Analysts believed there were real risks, especially in countries with large solar installations like Germany and Italy [7]. Prague, Czech Republic, had a partial solar eclipse on this day. A study conducted by Libra et al. [8] explained the behavior of a laboratory 510 peak watt PV system during the eclipse and explained in terms of a theoretical model taking into account the temperature and wind speed. It correlated the module power to the measured incident irradiance. 


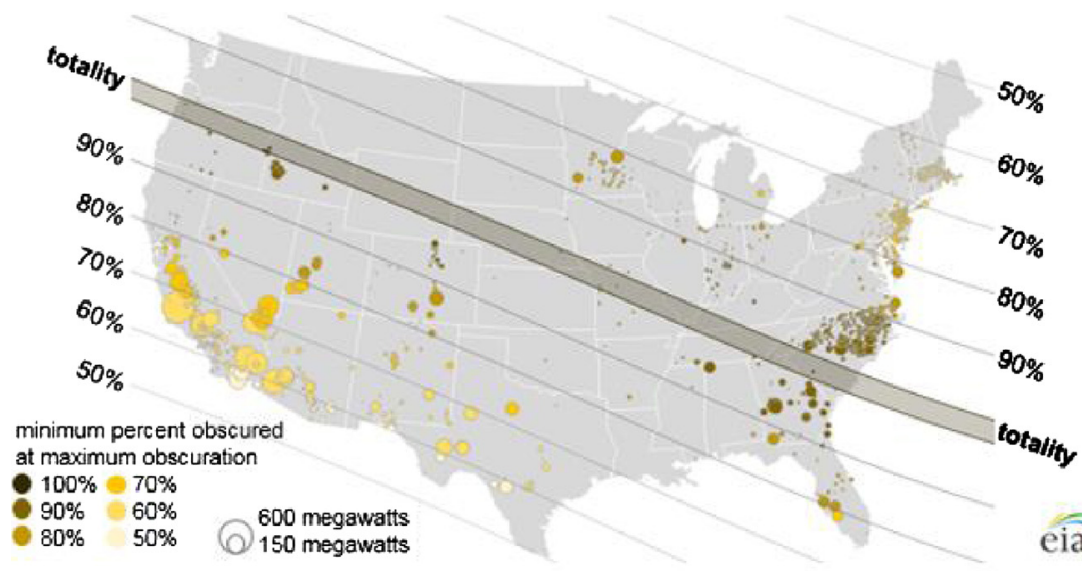

(a)

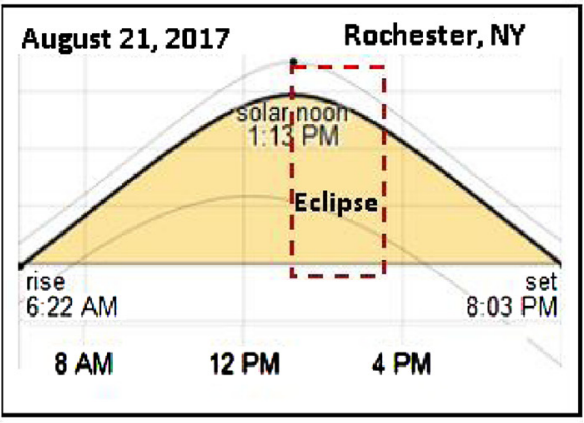

(b)

Fig. 1. (a) Utility scale photovoltaic generators and the path of August solar eclipse; Source: U.S. Energy Information Administration, Preliminary Monthly Electric Generator Inventory and National Aeronautics and Space Administration (NASA) [3]; (b) Eclipse time and day length in Rochester, NY [4].
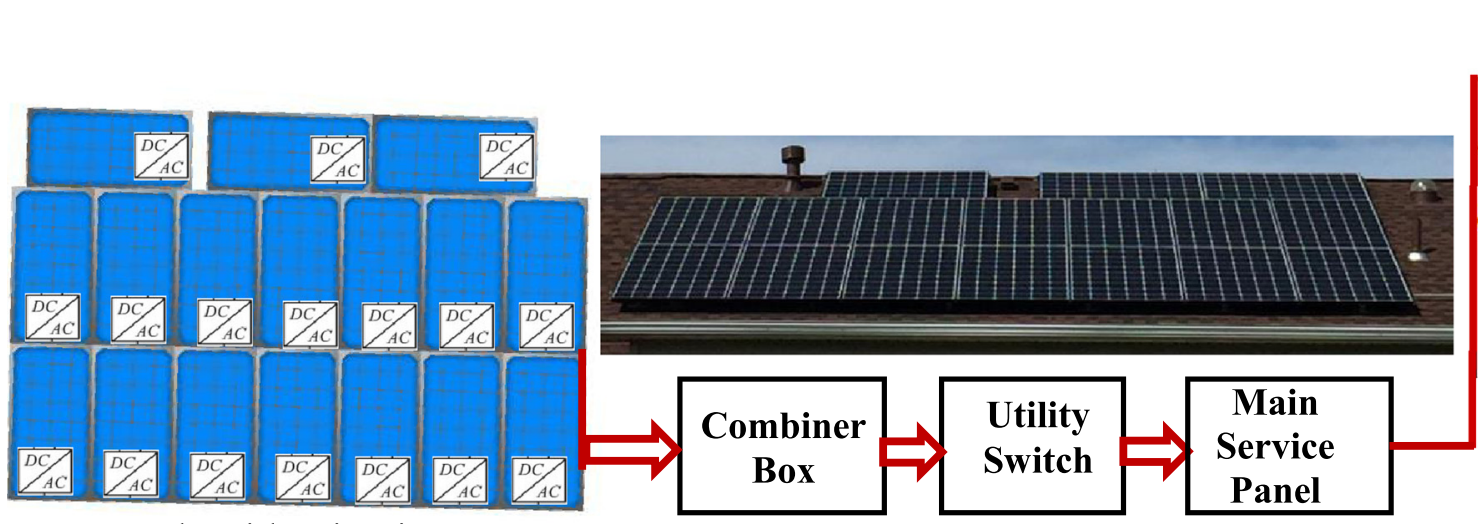

17 Panels with microinverters

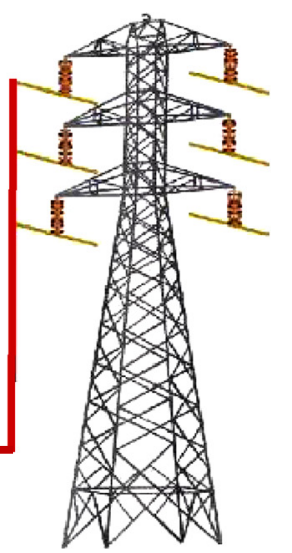

Fig. 2. Schematic of the grid connected PV system with photograph of the panels.

The study presented in our paper correlates the observed energy produced by an operating residential PV system to the calculated values during the eclipse using the model incorporating eclipse coverage, change in efficiency, system efficiencies and clearness index.

The PV system investigated is shown in Figure 2. It consists of seventeen monocrystalline silicon solar panels with a rated efficiency of $17.4 \%$ at the Standard Test Conditions (STC). The panels are tilted at an angle of 26 degrees from horizontal with an azimuth angle of $178^{\circ}$ facing south. The solar production and energy consumption data is monitored using the Enphase Envoy-S gateway communication system [9].

\section{Background}

\subsection{Solar insolation}

Figure 3 defines the various angles involved in the calculation of solar irradiance on the solar panels. The solar zenith $z$, or altitude $\alpha$ and azimuth angle $\Psi$ are calculated for a location specifying its latitude $L$, longitude $\phi$, the date and time of the day. The total irradiance incident on the solar panels taking into account the module tilt angle $\beta$ and azimuth angle $\gamma$ can then be calculated [10-14].

The global irradiance that is incident on a surface is the sum of direct beam, diffused and reflected components. While direct beam depends on the position of the sun, diffuse and reflected components also depend on atmospheric and ground conditions [15].

The global solar insolation on an inclined surface is expressed as

$$
\begin{aligned}
I_{G}^{T}= & I_{B}^{H}\left(\frac{\cos \theta}{\cos z}+\frac{\rho(1-\cos \beta)}{2}\right) \\
& +I_{D}^{H}\left(\frac{(1+\rho)+(1-\rho) \cos \beta}{2}\right) .
\end{aligned}
$$

The superscripts $T$ and $H$ refer to tilted and horizontal surfaces respectively, and subscripts $G, B$, and $D$ refer to global, direct beam, and diffused irradiation respectively. The reflection component is defined in terms of the reflection coefficient $\rho$ of the ground surrounding the 


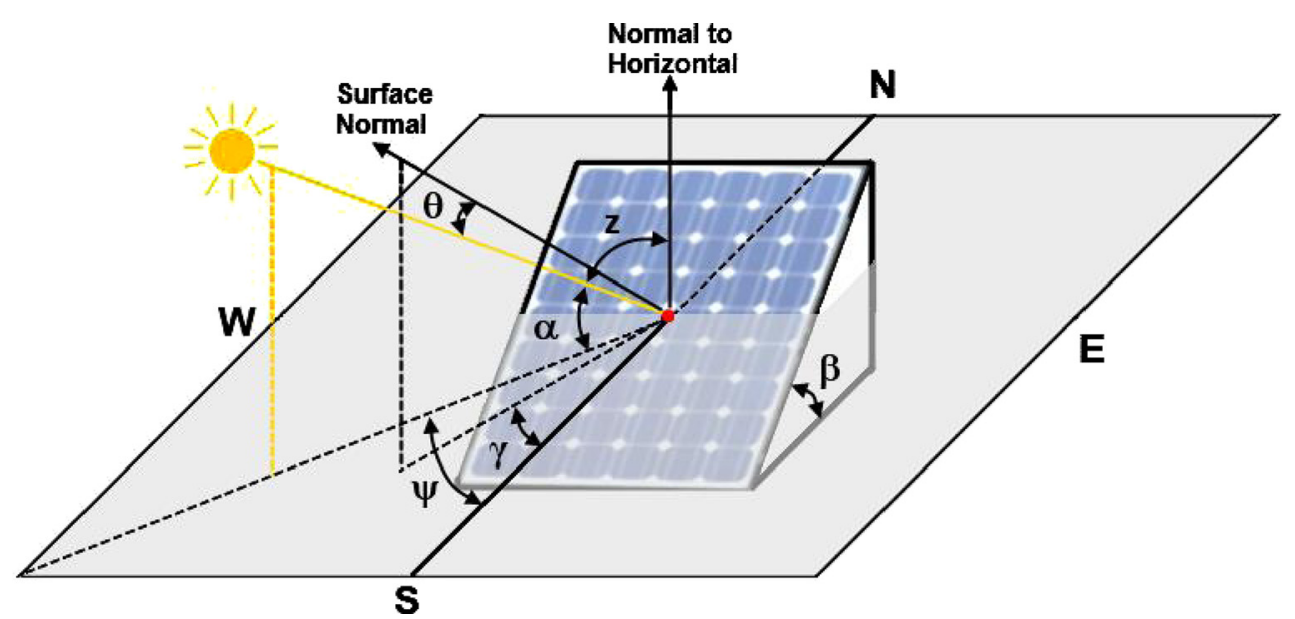

Fig. 3. Definition of various angles related to the position of the Sun and panel orientation.

surface. The direct beam radiation on a horizontal surface is given by

$$
\begin{aligned}
I_{B}^{H}= & I_{0}\left(1+0.033 \cos \left(2 \pi \frac{n-4}{365}\right)\right) \\
& \times \exp \left[-0.8662 m D_{R}(m) T_{L}\right] \cos z,
\end{aligned}
$$

where $I_{0}$ is the solar constant, taken as $1360 \mathrm{Wm}^{-2}, n$ is the day of the year according to the Julian calendar, $m$ is the air mass, $D_{R}(m)$ is the Rayleigh scattering optical depth, and $T_{L}$ is the Linke turbidity factor [16-18].

An empirical formula derived by Kasten \& Young (1989) in [16] is used to calculate the air mass

$$
m=\frac{1}{\cos z+0.50572(96.07995-z)^{-1.6364}},
$$

where $z$ is the angle the Sun makes with the zenith. The Linke turbidity factor, $T_{L}$ is defined as the number of Rayleigh atmospheres necessary to represent the actual optical thickness $D(m)$.

$$
T_{L}=\frac{D(m)}{D_{R}(m)} .
$$

Rayleigh scattering optical depth $D_{R}(m)$ is calculated using the empirical equation [18]

$$
\begin{aligned}
D_{R}(m)= & {\left[6.6296+1.7513 m-0.1202 m^{2}\right.} \\
& \left.+0.0065 m^{3}-0.00013 m^{4}\right]^{-1} .
\end{aligned}
$$

Regarding inclusion of diffused radiation, the underlying concept was originally proposed by Liu and Jordan [15]. One of the useful ways to determine the extent of cloudiness or the degree of clearness of the sky is through some mathematical relationships among the available solar fluxes like global radiation, diffuse radiation and extraterrestrial radiation. Two parameters, inter relating these fluxes are defined as:

The diffuse fraction of horizontal radiation, $K_{D}$

$$
K_{D}=\frac{\text { Diffuse horizontal radiation }}{\text { Global horizontal radiation }}=\frac{I_{D, H}}{I_{G, H}},
$$

and the clearness index, $K_{C}$

$$
\begin{aligned}
K_{C} & =\frac{\text { Global horizontal radiation }}{\text { Extraterrestrial horizontal radiation }} \\
& =\frac{I_{G, H}}{I_{\text {extra }, H}} .
\end{aligned}
$$

Note that the clearer the atmosphere, the higher the radiation and the lower the diffuse content. Hence, $K_{\mathrm{D}}$ and $K_{C}$ are expected to be negatively correlated. Division by the extraterrestrial radiation eliminates the radiation variations due to the apparent motion of the sun. This way, the correlation between $K_{\mathrm{D}}$ and $K_{C}$ becomes independent of latitude effects, and, in principle, tends to be of universal validity. Various empirical formulae are available. A correlation for this study to define solar radiation characteristics, employed the following model of diffused fraction related to the clearness index as $[19,20]$

$$
\begin{aligned}
K_{D} \approx\left\{\begin{array}{l}
0.98, K_{C} \leq 1 \\
0.910+1.15 K_{C}-4.936 K_{C}^{2}+2.848 K_{C}^{3}
\end{array},\right. \\
0.1 \leq K_{C} \leq 0.7 .
\end{aligned}
$$

A complete flow chart of irradiance calculations is described in Figure 4.

\subsection{Eclipse progression}

On August 21, 2017, the Sun was $152092505 \mathrm{~km}$ from the Earth subtending an angle of 0.524 degrees at the Earth's surface. The Moon was at Perigee position at a distance of $366127 \mathrm{~km}$ subtending a very close angle of 0.54 degrees, slightly higher, which caused the eclipse totality at certain locations [21]. Assuming the radius of the Sun's disk to be unity, the radius of the Moon disk was 1.0305.

Figure 5 shows a schematic of the situation when the Moon has encroached in front of the Sun by a distance $d$. With solar radius and lunar radius each assumed unity, it can be inferred that, $d=0$ at the first contact, $d=2$ at the second contact causing the total eclipse condition [22]. 


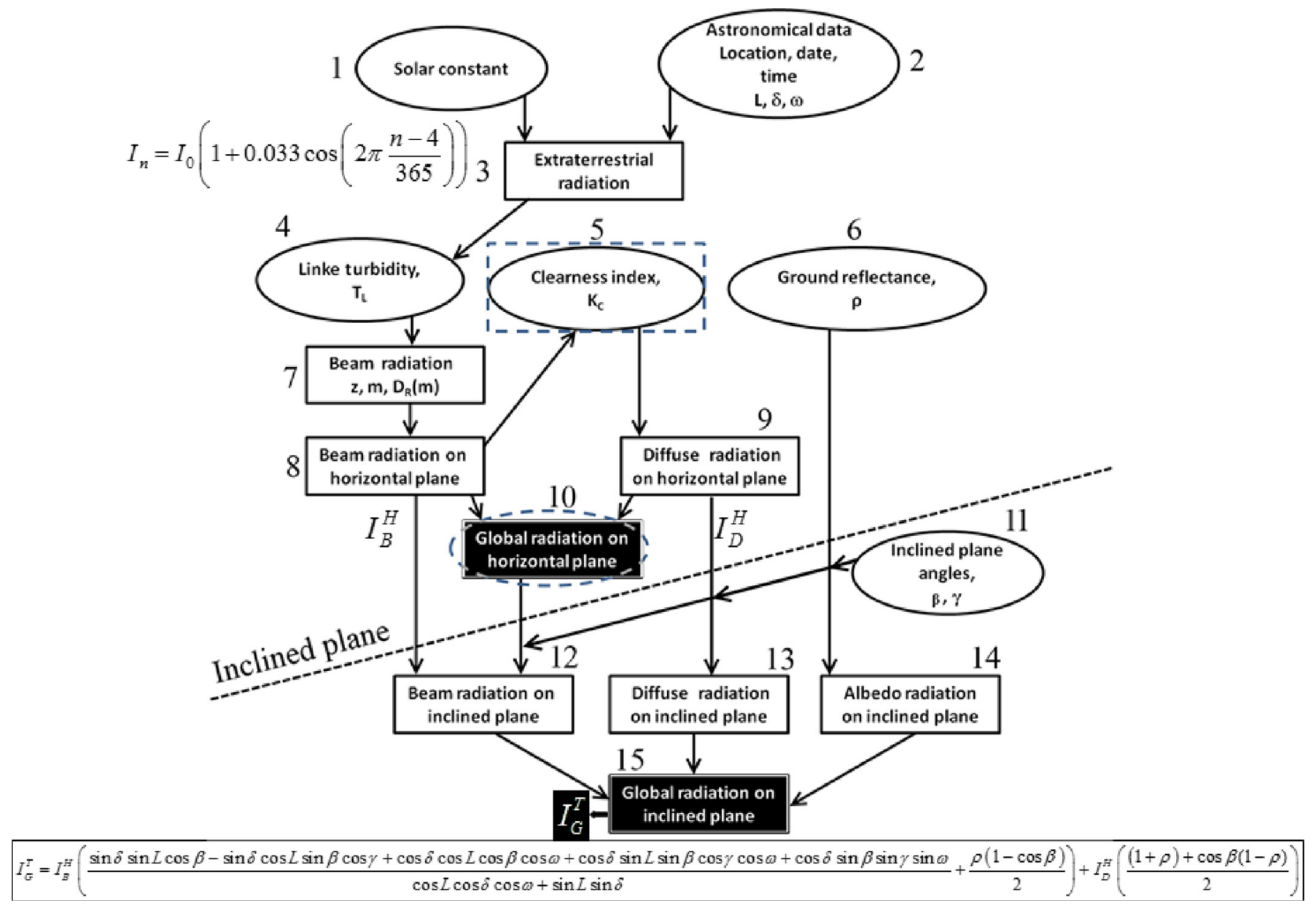

Fig. 4. Flow chart showing the steps used in irradiance calculations with key equations.

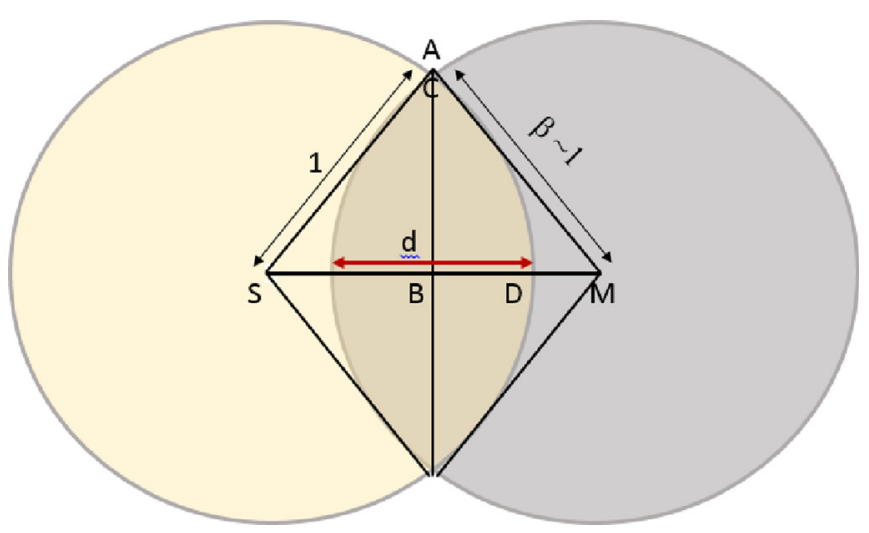

Fig. 5. Calculation of exposed area of the solar disk with Moon encroaching by a distance $d$ in units of the Sun radius.

The area of the eclipsed part of the solar disk can be written as

$$
\begin{aligned}
A_{\text {eclipsed }} & =\frac{\pi}{90^{\circ}} \sin ^{-1} \sqrt{1-\left(1-\frac{d}{2}\right)^{2}} \\
& -|(2-d)| \sqrt{1-\left(1-\frac{d}{2}\right)^{2}} .
\end{aligned}
$$

With the area of the Sun, $A_{\text {sun }}$ being $\pi$, the ratio of the exposed part of the Sun, $A_{d}$ is expressed as

$$
\begin{aligned}
A_{d} & =\frac{A_{\text {exposed }}}{A_{\text {sun }}}=\frac{A_{\text {sun }}-A_{\text {eclipsed }}}{A_{\text {sun }}} \\
& =1-\frac{\sin ^{-1} \sqrt{1-\left(1-\frac{d}{2}\right)^{2}}}{90^{\circ}}+\frac{|(2-d)| \sqrt{1-\left(1-\frac{d}{2}\right)^{2}}}{\pi},
\end{aligned}
$$

and is plotted in Figure 6 .

\subsection{Photovoltaics system}

A PV system consists of solar cells connected in series and parallel configurations into modules and arrays to design the output requirements of power, voltage and current. A solar cell is essentially a diode ( $\mathrm{PN}$ junction) converting absorbed solar photon flux with energy $>E_{g}$, the bandgap of the semiconductor into electron hole pairs. The minority carriers (electrons in $P$ side and holes in $N$ side) then diffuse and cross the diode depletion width giving rise to a voltage drop across the load, generating power [23].

Solar cell efficiency $\eta$ is defined as the percentage of the ratio of the maximum power output to the incident solar 


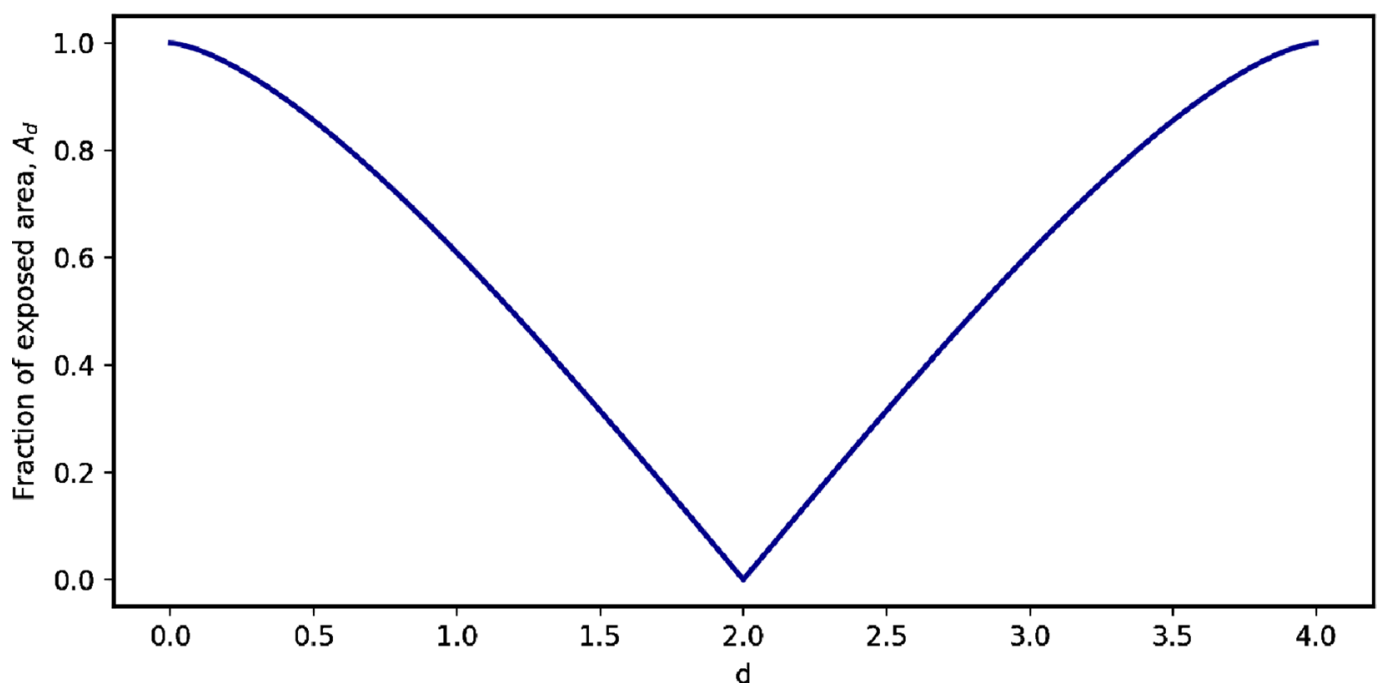

Fig. 6. Percentage of solar disk area exposed as a function of $d$. First contact $d=0$, second contact $d=2$ and exit at $d=4$.
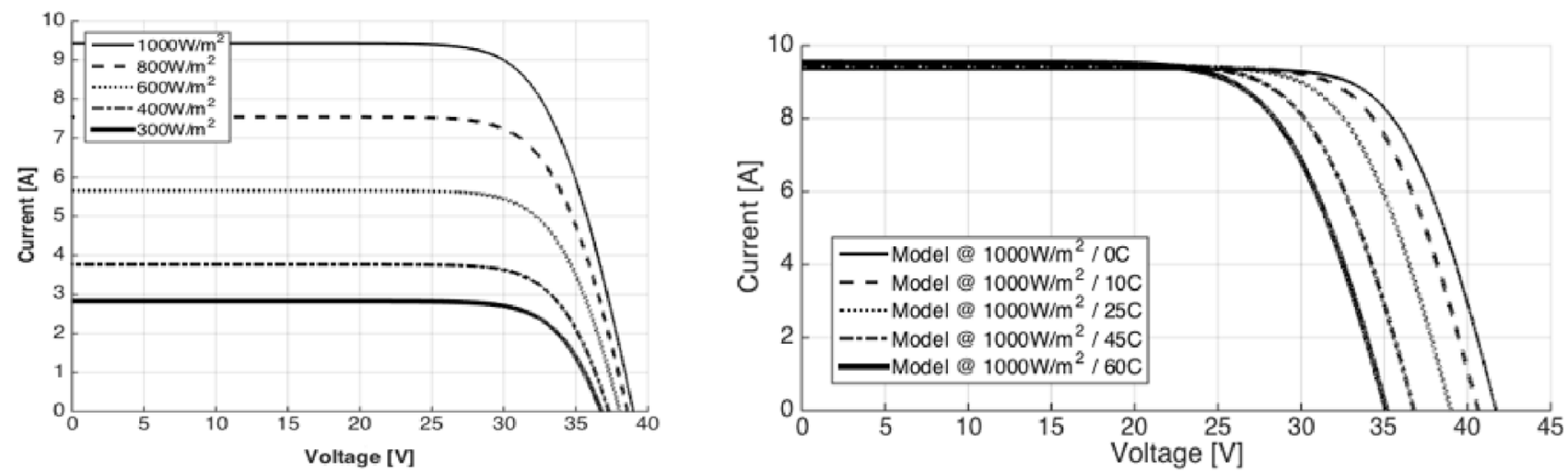

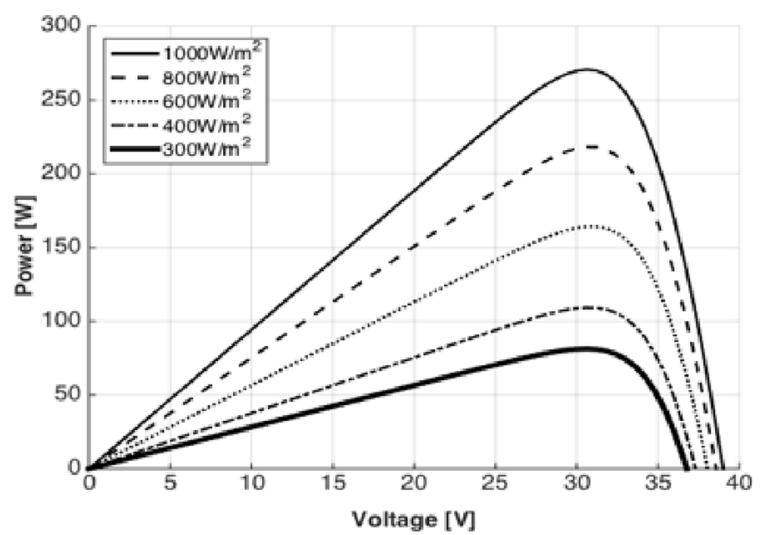

(a)

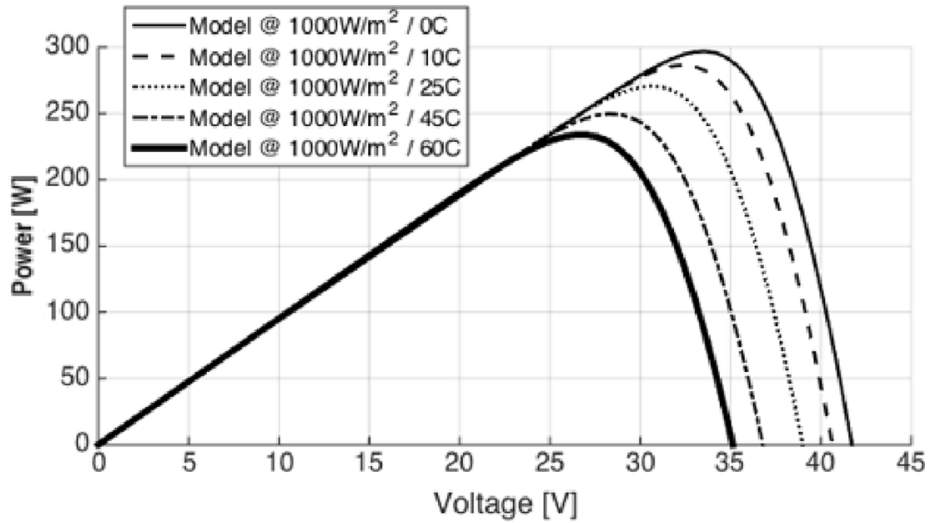

(b)

Fig. 7. Modeled current-voltage/power-voltage characteristics at different irradiation levels for $25^{\circ} \mathrm{C}$; (b) current-voltage/powervoltage characteristics at different temperatures for an irradiance of $1000 \mathrm{Wm}^{-2}$.

insolation at STC. (Irradiance $1000 \mathrm{Wm}^{-2}$, module temperature $\left.25^{\circ} \mathrm{C}, \mathrm{AM} 1.5\right)$.

$$
\eta(\%)=\frac{P_{\mathrm{MAX}}}{P_{\mathrm{in}}} \times 100=\frac{V_{\mathrm{mp}} I_{\mathrm{mp}}}{P_{\mathrm{in}}} \times 100 .
$$

When cells are connected in series, the voltages add up and when connected in parallel, the currents add up assuming identical cells. The electric power produced by the $\mathrm{PV}$ panels is DC and inverters are used to convert DC to AC. Also, to protect the modules against shading effects, bypass diodes are used. Overall, a PV system consists of PV arrays, bypass diodes, inverters, combiners and metering devices. 
Table 1. Electrical specification of LG Mono LG-285S1CG4.

\begin{tabular}{ll}
\hline Electrical properties $(\mathrm{CTC})$ & \\
Module power $P_{\mathrm{MAx}}, \mathrm{W}$ & 285 \\
Rated voltage $V_{\mathrm{mpp}}, \mathrm{V}$ & 32.3 \\
Rated current $I_{\mathrm{mpp}}, \mathrm{A}$ & 8.88 \\
Open circuit Voltage $V_{\mathrm{OC}}, \mathrm{V}$ & 39.0 \\
Short circuit Current $I_{\mathrm{SC}}, \mathrm{A}$ & 9.43 \\
Maximum system voltage, V & 1000 (IEC, UL) \\
Module efficiency $\%$ & 17.4 \\
Max series fuse rating, A & 15 \\
Inverter + wiring efficiency & 0.85 \\
& \\
Temperature characteristics & \\
NOCT & $46 \pm 3{ }^{\circ} \mathrm{C}$ \\
Temperature coefficient of & $-0.42 \% /{ }^{\circ} \mathrm{C}$ \\
maximum power, $P_{T, \text { coeff }}$ & \\
\hline
\end{tabular}

The performance of a PV system depends on solar irradiance and temperature. Figure 7 shows the currentvoltage and power-voltage characteristics of the solar panels (Mono LG-285S1C-G4) used in this study. These characteristics are obtained using the method described in reference [24] with specifications provided by the vendor LG, also listed in Table 1.

\section{Results and discussion}

\subsection{Eclipse imaging}

The solar eclipse images were shot with a Canon XSi DSLR and a Stellarvue SV70T APO refractor at $\mathrm{f} / 4.8$ through Baader AstroSolar Safety Film. This astrophotography rig was attached to a German equatorial mount which tracked the movement of the sun across the sky. The camera was tethered to a PC which triggered images every $16 \mathrm{~s}$ throughout the eclipse. The representative cloud-free images were then selected for the montage and are shown in Figure 8. As observed the eclipse was partial reaching $70 \%$ coverage at 2:35 PM. The first contact happened at 1:13 PM and ended at 3:52 PM.

The times reported in this study are in Eastern Daylight Time (EDT) zone. EDT is $4 \mathrm{~h}$ behind Coordinated Universal Time (UTC). This time zone is a Daylight Saving Time (DST) zone. The area fraction $A_{d}$ of exposed solar disk is obtained from these images.

\subsection{PV output}

\subsubsection{Experimental data}

The PV system output measured in an interval of $15 \mathrm{~min}$ in units of Wh is plotted as a function of the time of the day for August 21, 2017 and compared with a day earlier August 20, 2017 and the same day a year ago in Figure 9. The data clearly shows a sharp decline during the eclipse time. A day after was very cloudy and rainy and no significant comparison could be made.

\subsubsection{Calculated data}

The irradiance on the solar panels, $P_{\text {in }}\left(\mathrm{Wm}^{-2}\right)$ is calculated using the flow chart of Figure 4, with the parameters and conditions provided in Table 2. The solar irradiance during the eclipse was determined by modifying the solar constant $I_{0}$ from $1360 \mathrm{Wm}^{-2}$ to $I_{0} \times A_{d}$, where $A_{d}$ is the exposed area of the solar disk (Fig. 10). To account for the cloudiness, the clearness index $K_{C}$, a measure of the clearness of the atmosphere is used. It is the fraction of the solar radiation that is transmitted through the atmosphere to strike the surface of the Earth. It is a dimensionless number between 0 and 1, defined as the global horizontal surface radiation divided by the extraterrestrial radiation. The clearness index has a high value under clear, sunny conditions, and a low value under cloudy conditions. The clearness index can be defined on an instantaneous, hourly, or monthly basis.

The clearness index $K_{C}$ was taken as an average value for the location [25] up until $2 \mathrm{PM}$. The cloud coverage increased after $2 \mathrm{PM}$ and $K_{C}$ value of 0.2 was estimated. The surrounding green farm around the PV system was characterized with the ground reflectivity of 0.2 . The solar cell short circuit current is directly proportional to the incident radiation. Therefore, the short circuit current of a reference small panel was monitored by measuring it every $500 \mathrm{~ms}$ and is shown in Figure 11.

The data shows increased cloud intermittence during the eclipse time. However, the differences may exist between the reference cell data and actual incidence on the system panels due to cloud intermittency.

It must be noted that the eclipse may cause a change in the spectral content of solar radiation incident on the Earth. A study of 2015 [26] and 2007 [27] eclipses observed wavelength dependent changes in the measured solar spectra showing a much more pronounced decrease in the radiation at the lower wavelengths $(<350 \mathrm{~nm})$. As different areas of the sun are covered during the eclipse, the radiation received at the top of the atmosphere is a combination of photons emerging from different regions of the Sun (corresponding to different temperatures - Limb Darkening effect), and hence its spectrum differs from that of the black body radiation that is usually considered. However, this change in spectrum has negligible effect on the silicon solar cells performance since most of the current contributions come from the wavelength range of 400$1000 \mathrm{~nm}$ in silicon [28].

The reduction of irradiance also causes decrease in the PV efficiency as current decrease linearly with irradiance and voltage deceases logarithmically. Assuming a single diode ideality factor, $n=1.2$ for the solar cells $\mathrm{I}-\mathrm{V}$ characteristics, the change in efficiency with concentration factor $N$, at $25^{\circ} \mathrm{C}$ is expressed as

$$
\frac{\Delta \eta}{\eta}=n(0.026) \frac{\ln N}{V_{\mathrm{oc}, \mathrm{STC}}},
$$




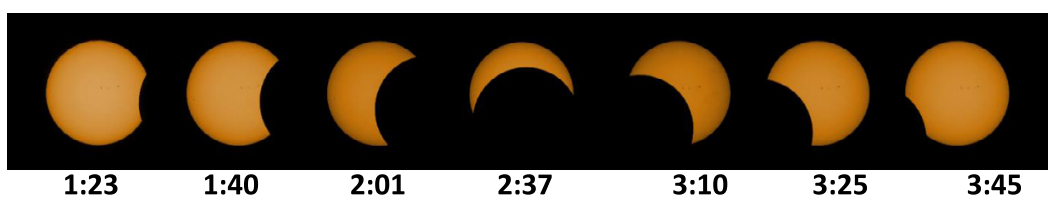

Fig. 8. Astrophotographs of the Sun taken at different times during the eclipse. The times are clock times in EDT.

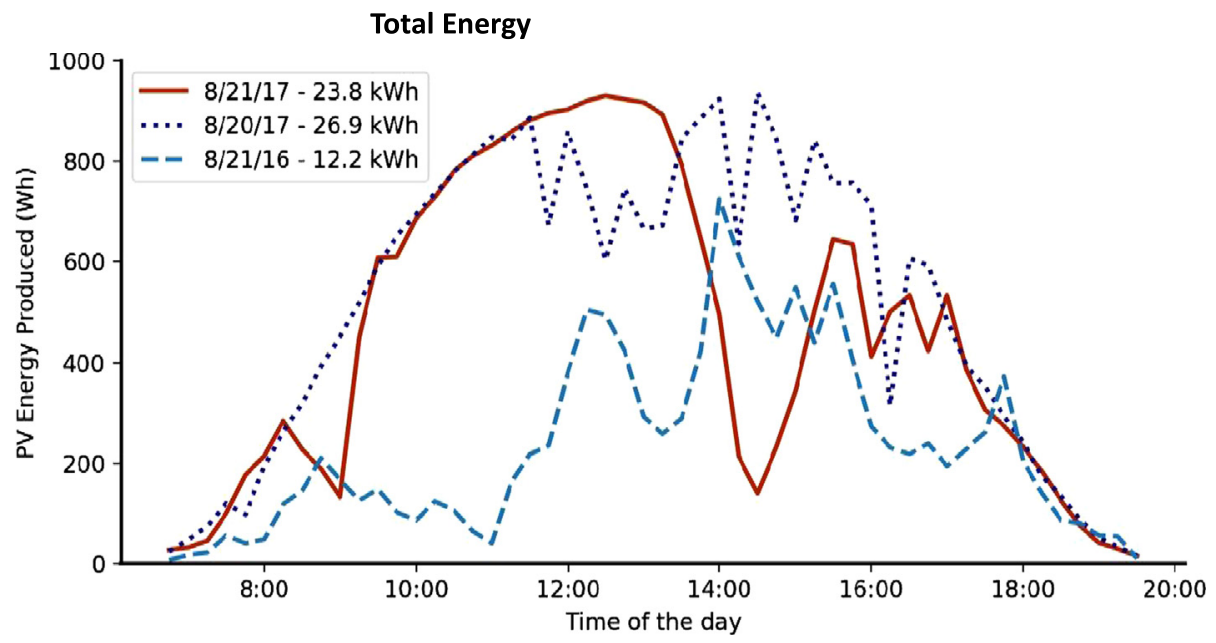

Fig. 9. Energy produced by the system during the day for August 21, 2017, August 20, 2017 and August 21, 2016.

Table 2. Parameters used in irradiance calculations.

\begin{tabular}{ll}
\hline Latitude & $43.16 \mathrm{~N}$ \\
Longitude & $77.6 \mathrm{~W}$ \\
$n$ (Day of the Year) & 233 \\
Module Tilt Angle, $\beta$ & $26^{\circ}$ \\
Module Azimuth Angle, $\gamma$ & $178^{\circ} \mathrm{S}$ \\
Solar Constant & $1360 \mathrm{Wm}^{-2}$ \\
Declination Angle, $\delta$ & $11.75^{\circ}$ \\
Ground Reflectivity, $\rho$ & 0.2 \\
Linke Turbidity, $T_{L}$ & 1 \\
Clearness Index, $K_{C}$ & 0.5 for time $<2 \mathrm{PM}$, \\
& 0.2 for time $>2 \mathrm{PM}$ \\
\hline
\end{tabular}

where $V_{\text {oc,STC }}$ is the open circuit voltage of the cell at STC. For the solar cells in this study, with a decrease in irradiance by a factor of $0.3, \Delta \eta=-0.057,5.7 \%$ decrease of efficiency occurs at the peak of the eclipse.

The PV efficiency also changes with temperature. Using the Normal Operating Cell Temperature (NOCT) model, the actual cell temperature is obtained as $[29,30]$

$$
T_{\text {cell }}=T_{\text {ambient }}+I \frac{\left(\mathrm{NOCT}-20^{\circ} \mathrm{C}\right)}{800 \mathrm{~W} \mathrm{~m}^{-2}},
$$

where $I$ is the incident irradiance. The power of the panel at the cell temperature $T_{\text {cell }}$ is then calculated as

$$
P=P_{\mathrm{STC}}+P_{T, \text { coeff }}\left(T_{\text {cell }}-25^{\circ} \mathrm{C}\right),
$$

where $P_{\mathrm{STC}}$ is the specified maximum power of the module at STC conditions. The temperature coefficient of the efficiency variation, $P_{T, \text { coeff }}$ in the modules used in this study is rated as $-0.42 \% /{ }^{\circ} \mathrm{C}$. The temperature measured during the eclipse was in the range of $24^{\circ} \mathrm{C}-26^{\circ} \mathrm{C}$ which yielded a cell temperature in the range of $38-50^{\circ} \mathrm{C}$. In addition to the PV efficiency, efficiency loss from the inverters, AC wiring and combiners are also considered. Given from the specifications, a system efficiency of $\eta_{\text {system }}$ of 0.85 is included. The energy produced from 17 modules of $1.49 \mathrm{~m}^{2}$ area each generated within $15 \mathrm{~min}$ interval is then given by

$$
E_{\text {out }}=P_{\text {in }}(1.49 \times 17) \times \eta_{\text {cell }} \times \eta_{\text {system }} \times 0.25 \mathrm{Wh},
$$

where $P_{\text {in }}$ is the incident irradiance on the panels, $\eta_{\text {cell }}$ is the cell efficiency taking into account the change in irradiance and temperature. In order to correlate the PV output with the eclipse progression, the PV energy produced is plotted as a function of time in a magnified scale in Figure 12. The results agree with our theoretical model that involves modifying solar constant and using the atmospheric conditions of cloudy $\left(K_{C}=0.2\right)$, and green grass with 


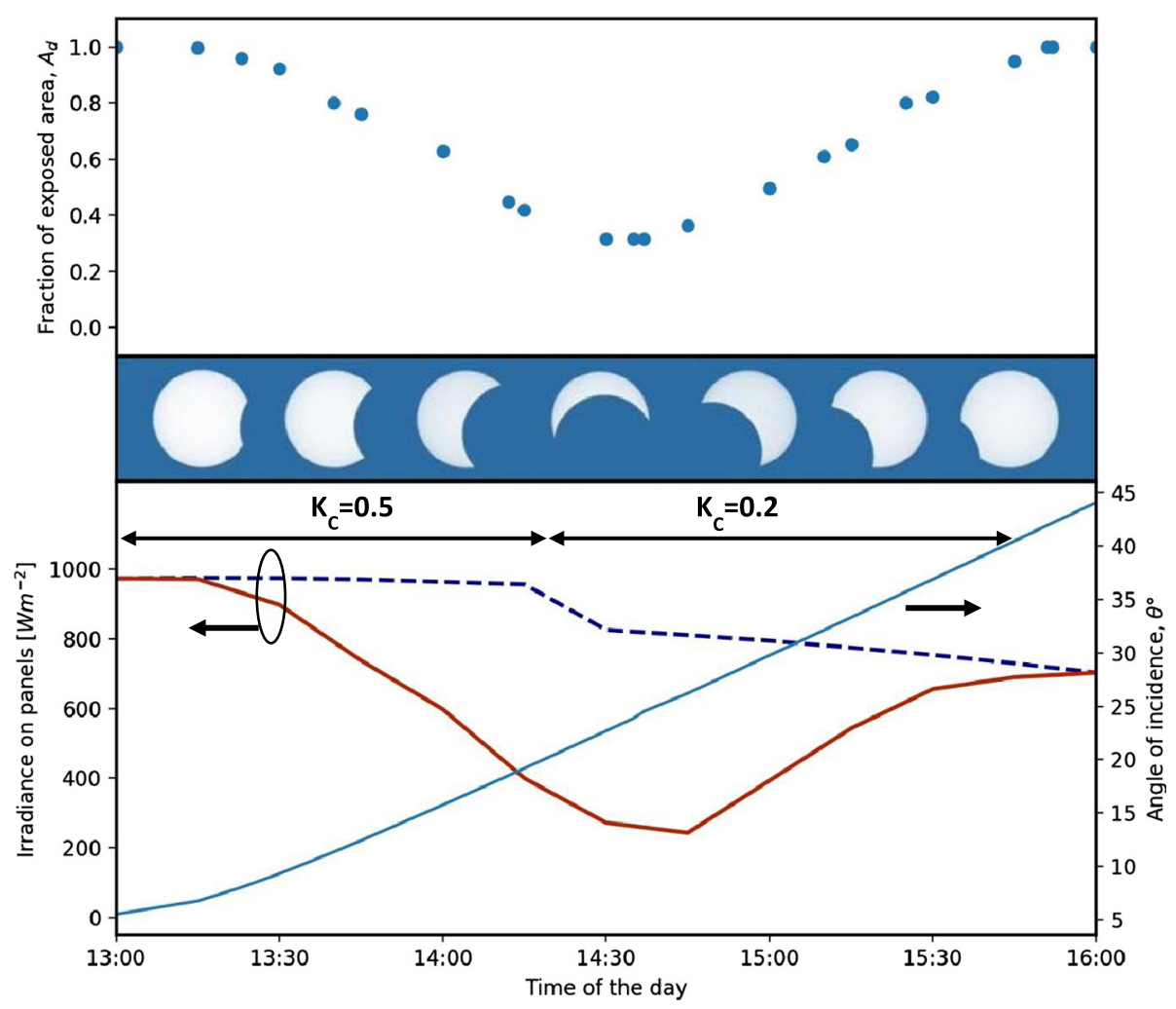

Fig. 10. Fraction of solar disk exposed $A_{d}$; angle of incidence, and irradiance on the panels during the eclipse. Irradiance calculated without eclipse is also shown for comparison.

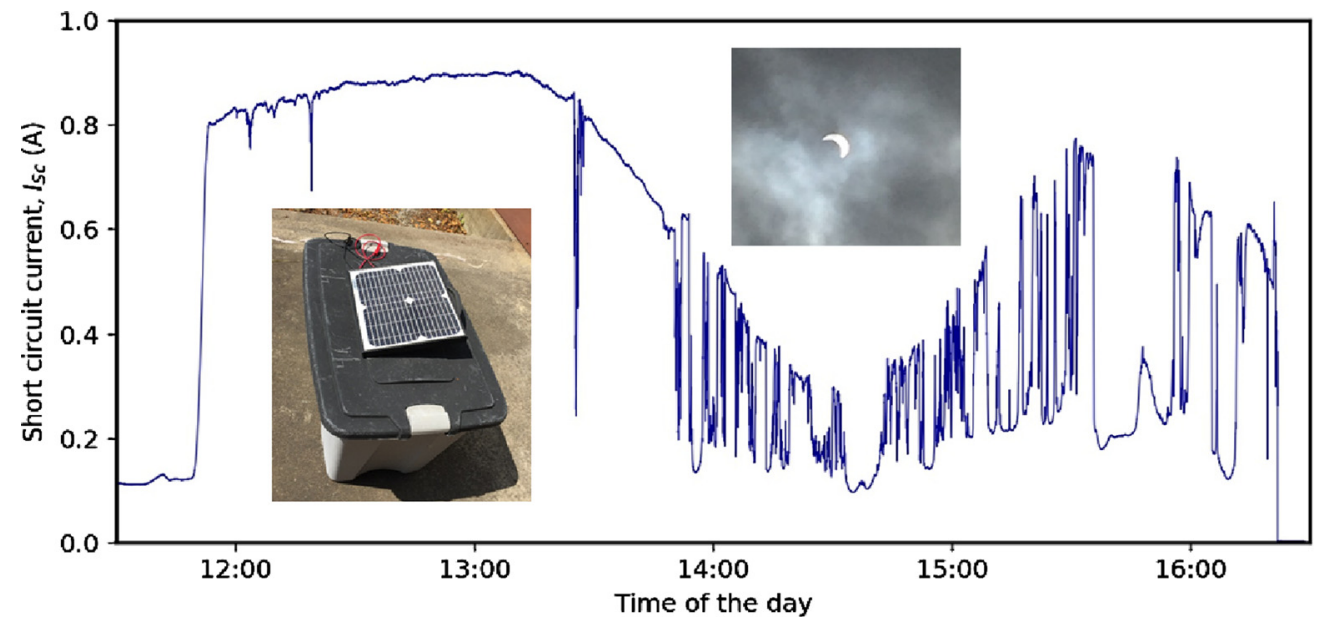

Fig. 11. Short circuit current of a reference small panel (picture in the inset) during the eclipse. Inset above shows a sky photograph of cloudy conditions at the time of the eclipse.

reflectivity $(\rho=0.2)$ from surrounding the panels. The differences observed are attributed to the intermittence nature of clouds. The model is underestimating before the eclipse progression and slightly overestimating after the peak. This suggests that the factors like air mass, Rayleigh optical depth, and clearness index may be changing with weather pattern and cloud intermittence. The theoretical energy output that would be expected if the eclipse did not happen is also shown. Approximately, a $3.5 \mathrm{kWh}$ energy loss is estimated due to the $2 \mathrm{~h} 25$ min eclipse. The $80 \%$ drop in energy produced observed includes reduction of incident irradiance by $\sim 70 \%$, and $\sim 6 \%$ decrease in PV efficiency.

It is observed at around 2.35 PM even though the sky did not appear $80 \%$ dark. This is due to the logarithmic nature of the response of the human eye to the differences in brightness. It has been reported that more than $93.5 \%$ of the solar disk has to be covered by the Moon for eclipse to be noticeable which happens a few minutes before totality [22]. 


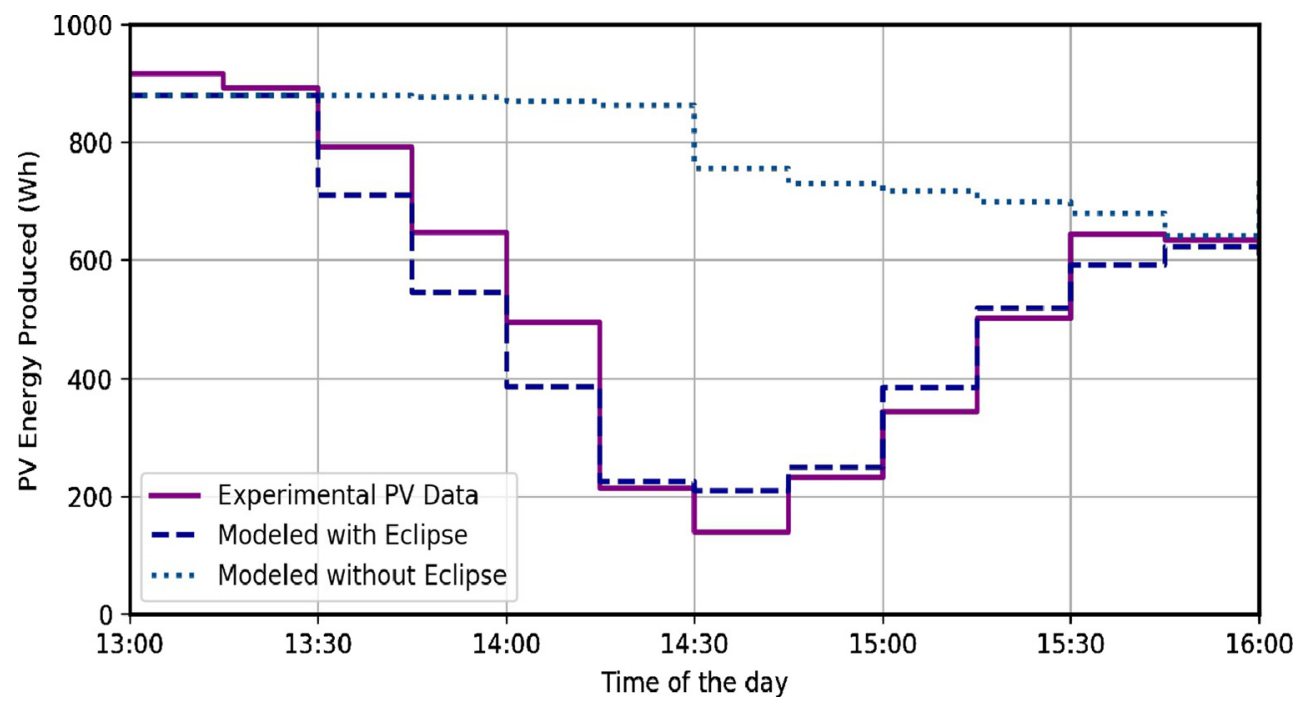

Fig. 12. Experimental data of energy produced compared with the calculated data.

Earth typically experiences anywhere from four to seven eclipses in a year, counting partial solar eclipses and lunar eclipses. On Mars, however, solar eclipses are practically a daily event. Mars has two moons - named Phobos and Deimos. Phobos' close, fast orbit makes it cross paths with the Sun near-daily causing annular eclipses. NASA's Mars rover Curiosity on August 20, 2013 photographed an annular eclipse [31] showing $69 \%$ of solar coverage. If one has to design a PV system for Mars, the effect of eclipse using similar calculations may be investigated using Martian conditions.

\section{Conclusions}

Most people consider eclipse to be by far the most spectacular natural phenomena they have ever witnessed, an "experience of a lifetime". It brings scientific curiosity amongst students, researchers and public in general. It ignites interests in astronomy, physics and related fields. The work reported in this paper is an example of authors from physics, electrical engineering, imaging science and astronomy to get together in carrying out this experiment showing the effect of eclipse on the PV system performance. It combines the concepts of radiation, PV design and system monitoring. A drop of $80 \%$ energy output is observed at the peak of the eclipse due to a $70 \%$ partial eclipse accompanied with cloudy atmosphere. A total loss of $3.5 \mathrm{kWh}$ is estimated due to the Sun's coverage during the eclipse. The eclipse obscured the sunlight at approximately 1900 utility-scale solar PV power plants in the U.S. Nationwide, the eclipse caused a temporary loss of an estimated $9000 \mathrm{MW}$ of solar power, including $4300 \mathrm{MW}$ in California [32].

The authors would like to thank Felipe Freire, Sharenergy, Brazil for his valuable contributions in modeling solar panel characteristics. Special thanks to Dr. Clark Hochgraf, Associate Professor of Electrical, Computer, and Telecommunications Engineering Technology, Rochester Institute of Technology, for help in monitoring reference panel short circuit current.

\section{Author contribution statement}

S. Kurinec and M. Kucer monitored the energy production data and modeled the irradiance during the eclipse. B. Schlein performed the astro imaging during the eclipse. All authors have contributed to the writing of the manuscript.

\section{References}

1. J.M. Pasachoff, A. Fraknoi, Am. J. Phys. 85, 485 (2017)

2. M. Zeiler, GreatAmericanEclipse.com, State by State maps of the Eclipse Path: https://www.greatamericaneclipse. $\mathrm{com} /$ (see the menu of States).

3. Solar eclipse on August 21 will affect photovoltaic generators across the country, Today in Energy, August 7, 2017. US Energy Information Administration, https://www.eia.gov/ todayinenergy/detail.php?id $=32372$

4. https://weatherspark.com/d/21245/8/20/Average-Weath er-on-August-21-in-Rochester-New-York-United-States\# Sections-SolarEnergy

5. E. Bellini, Global installed PV capacity exceeds $300 \mathrm{GW}$, IEA PVPS, PV Magazine, April 25, 2017

6. https://www.nrdc.org/experts/julia-prochnik/how-willeclipse-affect-solar-power

7. Solar Eclipse 2015, Impact Analysis, European Network of Transmission Systems Operators for Electricity, February 19, 2015, https://www.entsoe.eu/Documents/Publications/ SOC/150219_Solar_Eclipse_Impact_Analysis_Final.pdf

8. M. Libra, P. Kouřím, V. Poulek, Int. J. Photoenergy 2016 , $2653560(2016)$

9. https://enphase.com/en-us/company

10. D. Goswami, F. Kreith, J.F. Kreider, Principles of Solar Engineering, 2nd edn. (Taylor \& Francis, Philadelphia, 2000)

11. PVeducation.org/Properties of sunlight

12. https://www.pvlighthouse.com.au/

13. T.D. Brock, Ecol. Model. 14, 1 (1981)

14. M. Iqbal, An Introduction to Solar Radiation (Academy Press, New York, NY, 1983)

15. B.Y.H. Liu, R.C. Jordan, Sol. Energy 4, 1 (1960) 
16. F. Kasten, A.T. Young, Appl. Opt. 28, 4735 (1989)

17. F. Kasten, Sol. Energy 56, 239 (1996)

18. A. Louche, G. Peri, M. Iqbal, Sol. Energy 37, 393 (1986)

19. L.T. Wong, W.K. Chow, Appl. Energy 69, 191 (2001)

20. Y.K. Sanusi, M.O. Ojo, IOSR-JAP 7, 45 (2015)

21. J. Mottmann, Am. J. Phys. 48, 626 (1980)

22. D.W. Hughes, J. Br. Astron. Assoc. 110, 203 (2000)

23. A. Devasia, S. Kurinec, Am. J. Phys. 79, 1232 (2011)

24. F. Freire, R. Dias, T. Trabold, S.K. Kurinec, IEEE 43rd Photovoltaic Specialists Conference (PVSC) (2016), pp. 2657-2660

25. https://www.nrel.gov/docs/legosti/old/7904.pdf
26. J. Gröbner, S. Kazadzis, N. Kouremeti, L. Doppler, R. Tagirov, A.I. Shapiro, AIP Conf. Proc. 1810, 080008 (2017)

27. S. Kazadzis, A. Bais, M. Blumthaler, A. Webb, N. Kouremeti, R. Kift, B. Schallhart, A. Kazantzidis, Atmos. Chem. Phys. 7, 5775 (2007)

28. http://www.pveducation.org/pvcdrom/solar-cell-opera tion/quantum-efficiency

29. M. Bayrakci, Y. Choi, J.R.S. Brownson, Energy Procedia 57, $745(2014)$

30. M. Muller, Measuring and modeling Nominal Operating Cell Temperature (NOCT). NREL Report PR-520-49505

31. https://photojournal.jpl.nasa.gov/catalog/PIA17356

32. https://www.eia.gov/todayinenergy/detail.php?id $=32372$

Cite this article as: Santosh K. Kurinec, Michal Kucer, Bill Schlein, Monitoring a photovoltaic system during the partial solar eclipse of August 2017, EPJ Photovoltaics 9, 7 (2018) 